\title{
Professor Derek S. Henderson and the Fourier transform
}

\author{
Berthold K.P. Horn \\ Department of Electrical Engineering and Computer Science, \\ MIT, Cambridge, MA 02139, USA
}

\begin{abstract}
Derek Henderson played a critical role in the introduction and development of Computer Science at the University of the Witwatersrand - and, by the way, in my career as well. There were no Computer Science courses at Wits when I started my Bachelor of Science in Electrical Engineering studies in 1961. I did learn though at some point that a "computer" would soon arrive and be installed in the Electrical Engineering building. I didn't know what that might be, but it sure sounded interesting! To cut a long story short, because of Dr. Henderson's kindness, I was able to learn how to use it, and in 1965, Pieter Kritzinger and I ended up doing our Bachelor's thesis on a comparison of optimal signal filtering methods using analog and digital computers. This was on the Computer Centre's IBM 1620, which, by the way, was a lot less finicky than the analog computer with its numerous failure-prone op-amps that it was competing against.
\end{abstract}

After I graduated in 1965, Dr. Henderson was instrumental in getting me an appointment as junior lecturer and he asked me to teach Numerical Analysis --- which, at that time, was one of the few topics taught in Computer Science (Unfortunately, today, the pendulum has swung the other way, and a student who has taken such a course is rare).

Dr. Henderson asked me to use R.W. Hamming's 1962 text [1] on the subject. I remember that he liked the quote from Hamming: "The purpose of computing is insight, not numbers." Amongst other things, I learnt how to do discrete Fourier transforms fast. Mind you this was before Cooley and Tukey's paper became widely known. You see, Hamming showed how to do it for small composite numbers such as $n=4,6,8,12 \ldots$ and foolishly assumed that people would be able to generalize the idea without any further patronizing help from him! This helps explain a rather acerbic reference in the second edition (1973) of his text [2] where he says that the fast Fourier transform "...was rediscovered and adequately publicized...” by Cooley and Tukey (a comment that must have seemed odd to the reader who had not studied the first edition). So I learnt early on that the honor often does not go to the first, but the one with good public relation skills Actually, since then, I have heard that others had come up with basically the same idea in the 1950s, and actually even before that, going all the way back to Carl Friedrich Gauss in about 1805 in his work on predicting orbits of the asteroids Pallas and Juno (where he also invented least squares analysis) [3][4].

Soon after I started, Dr. Henderson introduced me to consulting. His work on behalf of the Computer Centre, the Department and the University precluded him taking on additional consulting work and so he funneled some to me. It turned out the South African navy was paying a lot every year to ICL in England to get predictions for the tides in the harbours. The actual predictions were apparently done on a large analog computer using coefficients computed from data collected over the previous year (no one 
really knew the details since it was considered a trade secret). Now I did know about Fourier transforms, having seen umpteen different versions in different courses. But this problem seemed not to fit because the driving forces (such as planetary and lunar orbital movements) were not harmonically related, while the discrete Fourier transform applies only to periodic discrete data. I couldn't use the equivalent of what was to become the FFT algorithm, because the DFT, of which the FFT is a fast implementation, applies only to discrete periodic data. But I was familiar with least squares methods, so in the end I worked out equations for least-squares fitting non-harmonically related sinusoids. The resulting set of equations was quite large, because of the considerable number of unknown parameters (such as higher harmonics of orbital periods and interactions between orbits). This meant that the job took quite a bit of computer time. But the "client" went off happy, able to save the navy a lot of money.

Not long after, much to my surprise, I saw my analysis and equations printed verbatim as an appendix in a paper presented at a conference in Monaco - without any attribution [5]! This inspired me to become more interested in publishing my own papers, and being careful about acknowledging the contributions of others.

During this time, Dr. Henderson also employed Manila Daya, counter to what the state at that time might have preferred. I got to know Mani well, but he was careful enough not to divulge even to his friends at the Computer Center that he was seeing Heike Rolle. Such was the state of affairs then. They married in Switzerland on their way to the USA. Manila studied at Harvard and had a successful career in computer science, retiring a few years ago from MITRE. Heike started a medical practice in Stoneham, Massachusetts.

At some point Dr. Henderson started negotiating, on behalf of the University, the acquisition of a larger computer, in the IBM 360 family. Numerous details needed to be worked out, including how to implement his dream of a time sharing system running a FORTRAN interpreter - both ideas at the time being revolutionary. Amongst other things, a way had to be found to interface multiple "terminals," which basically were glorified electric typewriters similar to the famed IBM Selectric (a few of you may remember those shiny golf balls gyrating wildly). This also meant essentially writing an operating system and a FORTRAN interpreter on top of the IBM supplied operating system. To facilitate all of this, he asked me to travel to a number of places in the United States and try and find bits and pieces of software, ideas and equipment to make this all possible. This was a thrilling experience for me. The only sad part is that years later I was made aware of the fact that Kathy Krige, a more senior member of the staff at the Computer Center, had been passed over for this assignment.

That trip allowed me to visit several Universities, take the GSAT examination, and be exposed to what were then cutting edge ideas in computer science. Just as an example of how things worked out, for one week, I rented a bike in Palo Alto and rode to Stanford Medical School every day, where, in return for some slave labour writing the debugging code of an operating system kernel in FORTRAN, I was ceremoniously given the magic code that would allow our system to talk to those electric typewriters! 
But that trip also gave me what I needed to apply to MIT, CMU and Stanford for graduate study. I chose MIT because the airfare was lower (I sometimes wonder about that decision while wandering beneath palm trees in the quad at Stanford). After my graduate studies at MIT, I returned to Wits and again Dr. Henderson was helpful in getting me some sort of position. I taught statistics in the Department of Surgery for a while. But I knew it was time to move on when one morning, after an all night road trip, a man with a thick Afrikaans accent waited outside my office door in the Gatehouse to "interview" me about my office mate Colin Marquard, who had somehow managed to skip out on a court date regarding some "communist" pamphlets that he was alleged to have been distributing.

In any case, I, and several others, owe the start of our careers to Dr. Henderson, who kindly let us "play" with the new computer. Some of the above may also help explain why I am still intrigued by problems related to the Fourier transform, and occasionally find little tidbits about it that I wasn't aware of before. Particularly ones that depend on mathematics that regrettably I didn't have time for in my undergraduate career at Wits. Curiously, one of Dr. Henderson's earliest scientific papers [6] shows familiarity with topics from number theory that are fundamental to my contribution "Interesting Eigenvectors of the Fourier Transform.”

\section{References:}

(1) Hamming, R. W. Numerical Methods for Scientists and Engineers, McGraw-Hill, 1962;

(2) Hamming, R. W. Numerical Methods for Scientists and Engineers, McGraw-Hill, second edition, p. 540, 1973;

(3) Heideman, M. T., D. H. Johnson, and C. S. Burrus, "Gauss and the history of the fast Fourier transform,” IEEE ASSP Magazine, 1, (4), pp. 14-21 (1984)

(4) Gauss, C. F., "Nachlass: Theoria interpolationis methodo nova tractata,” Werke, Band 3, pp. 265-327. Göttingen: Königliche Gesellschaft der Wissenschaften, 1866.

(5) Appendix I of "Recent Developments in Tidal Analysis in South-Africa,'” by A.M. Shipley, International Hydrographic Review, Monaco, April 1967, pp. 6670.

(6) Henderson, D. S., “Residue Class Error Checking Codes,” Proceedings of the $16^{\text {th }}$ International Conference of the ACM, September 1961. 